\title{
El CELA Superior dentro del Sistema de Certificación del CEPE
}

Eva

Campos Gómez y

Claudia

Cárdenas Sosa

CEPE-UNAM

INTRODUCCIÓN

El Certificado deEspañol como Lengua Adicional (CELA), nivel superior, complementa la serie de tres exámenes (inicial, intermedio y superior) destinados a validar el conocimiento y las destrezas que hablantes de otras lenguas poseen sobre el español.

Dada la importancia que la certificación del español ha ido adquiriendo en el ámbito de la enseñanza de lenguas a nivel internacional, en este artícul o se ofrece un panorama general sobre el Sistema de Certificación con que actualmente cuenta el Centro de Enseñanza para Extranjeros (CEPE), para terminar describiendo el CELA Superior (versión 2) último componente de dicho sistema.

\section{LA CERTIFICACIÓN}

Una prueba de certificación del español con alcance internacional debe cumplir con ciertos estándares para garantizar su credibilidad frente a la comunidad científica y ante los usuarios del servicio, por lo que, en seguida nos referiremos a ellos, aunque de manera muy general.

\section{LOS ESTÁNDARES}

El término estándares (o criterios) está relacionado con la noción de principios. Pollit ${ }^{1}$ considera los criterios como una forma de medir la adhesión de una institución a determinados princi pios. Los estándares proporcionan una base para evaluar la práctica de la evaluación; consisten

Charles J. Alderson, et. al, Exámenes de idiomas. Elaboración y evaluación. 
José Ramón Parrondo Rodríguez, Sistema Internacional de Certificación del Español, p. 3. en ciertas directrices acordadas por al guna institución, que deberían consultarse y tomarse en cuenta durantela elaboración y evaluación de una prueba.

La práctica deacreditación oficial deconocimientos del español es relativamente reciente, en comparación con la larga trayectoria que en este mismo campo tiene el inglés. Parrondo ${ }^{2}$ ofrece una lista de los sistemas de certificación de español que actualmente existen en diferentes ámbitos geográficos al rededor del mundo.

En América del Norte, el Ministerio de Inmigración canadiense ya cuenta con estándares definidos, y en Estados Unidos existen desde 1995 Ios National Standards for Foreign Language Education, elaborados por especial istas del American Council on the Teaching of Foreign Languages (ACTFL). En América del Sur, la situación es diferente, pues los sistemas de certificación del español todavía no están muy consolidados, ya que existen multitud de niveles y de denominaciones: certificados, exámenes, diplomas, títulos, etcétera. Esta diversidad, en ocasiones, genera cierta incertidumbre entre los consumidores en cuanto a confiabilidad, contenidos y respal do institucional.

\section{EL SICELE}

El pasado mes de marzo, en el marco del IV Congreso Internacional de la Lengua Española en Medellín, Colombia, se creó el Sistema Internacional de Certificación del Español como Lengua Extranjera (SICELE) promovido por la Universidad Nacional Autónoma de México (UNAM) y el Instituto Cervantes (IC). Este Sistema acreditará los diferentes exámenes que el aboren las universi dades de países iberoamericanos para certificar el conocimiento del español como lengua extranjera. Dicha certificación estará basada en model os de exámenes diseñados con criterios académicos, normas y procedimientos claramente establecidos, así como lineamientos de evaluación lingüística reconocidos internacional mente.

Para garantizar la calidad de la certificación, las universidades adheridas al SICELE, incluyendo Ia UNAM, se sujetan, de manera provisional, en cuanto a los conteni- 
dos a los estándares establecidos en el Marco Común Europeo de Referencia para las Lenguas: aprendizaje, enseñanza, evaluación (MCER), en tanto se crea una regulación interna que, al mismo tiempo observe los lineamientos del MCER, establezca sus propias escal as y las articula con las ya existentes.

Como es bien sabido, el MCER es un documento que ha marcado el rumbo de la enseñanza de lenguas extranjeras desde el año 2000, no solamente en Europa, sino en todo el mundo, ya que proporciona una basecomún para la elaboración de programas de lenguas, exámenes y manuales. Describe de forma integradora lo que tienen que aprender a hacer los estudiantes para comunicarse en la lengua meta, así como los conocimientos y destrezas que tienen que desarrollar para poder actuar de manera eficaz. Define también los niveles de dominio dela lengua que permiten comprobar el progreso de los al umnos en cada fase del aprendizaje.

Esta base común que ofreceel MCER parala descripción explícita de los objetivos, los contenidos y la metodología, favorece la transparencia de los cursos, los programas, la certificación y fomentala cooperación internacional en el campo de las lenguas modernas. La presentación de criterios objetivosque describen el dominio de la lengua facilita el reconocimiento mutuo delas certificaciones obtenidas en distintos contextos de aprendizaje y, consecuentemente, contribuye ala movilidad en Europa y en el mundo entero.

Los exámenes CIE y CELA se han elaborado bajo loslineamientos del MCER y por lo tanto, responden a los estándares exigidos por el SICELE.

\section{EL SISTEMA DE CERTIFICACIÓN DEL CEPE}

Estesistema está conformado por tres exámenes diferentes con objetivos específicos relacionados con el público a quien van dirigido, pues las demandas de acreditación han aumentado y se han diversificado en los últimos años. Actualmente las instituciones educativas y las empresas solicitan la acreditación de cierto nivel de conocimientos del español. Además, los estudiantes del CEPE con frecuencia piden al gún documento que avale 
Ios conocimientos que adquieren en los cursos (aun cuando no han terminado todo el programa) como comprobante de que aprovecharon la beca, el intercambio o al gún beneficio otorgado por sus instituciones de origen.

Para satisfacer éstas y otras necesidades el Sistema de Certificación del CEPE ha aumentado su oferta, que consiste en dos exámenes tipo score [Examen de Posesión de Ia Lengua Española (EPLE) y el Certificado Internacional de Español (CIE) ]. Y tres exámenes (CELA) que evalúan la lengua por niveles (inicial, intermedio y superior), entendiendo por nivel la descripción de lo que el candidato es capaz de hacer mediante el uso de la lengua.

\section{EL EPLE}

El Examen dePosesión dela Lengua Españolafueel primer instrumento que se desarrolló en el CEPE con el objeto de acreditar el dominio de lengua de los extranjeros que año con año requieren comprobar su nivel de español para desempeñarse en actividades académicas, laborales, profesionales u otras.

El EPLE es un examen tipo scoreque evalúa de manera progresiva los conocimientos lingüísticos de los candidatos para lo cual se requiere el uso de habilidades cognoscitivas complejas.

\section{EL ClE}

El Certificado Internacional de Español aspira a ser reconocido por el SICELE y, por diferentes universidades ubicadas en países de habla hispana; pretende, asimismo, constituir un model o para el diseño de exámenes o sistemas de evaluación propuestos por otros países.

El CIE es un examen diseñado específicamente con fines académicos, su objetivo es diagnosticar el nivel de competencia lingüística de los candi datos que desean cursar estudios superiores en español. Este examen evalúa progresivamente los niveles B1, B2 y C (MCER). 
El hecho de que desde sus inicios el CIE haya estado enfocado hacia la academia marcó la tendencia para su elaboración; es decir, uno de los factores que influyen de manera importante en su resolución exitosa es la capacidad de parte del sustentante para enfrentarse a textos incluso especializados, así como a la producción de escritos con un alto nivel académico. Es por ello, queel público destinatario del $\mathrm{CIE}$ son profesionales del ámbito académico.

\section{EL CELA}

El proyecto de Certificación del Español como Lengua Adicional (CELA) surge como respuesta a un convenio cel ebrado con la Universidad de Sal amanca en 2002. Por esa época, el modelo que preval ecía para certificar el dominio del español en Europa era el de los exámenes DELE (Diploma de Español como Lengua Extranjera) elaborados por la propia Universidad de Sal amanca y aplicados por el IC.

El proyecto CELA, en sus inicios, se desarrolló tomando como modelo IOS DELE, pero posteriormente fue tomando personalidad propia al sujetarse a los lineamientos del Nuevo Plan de Estudios del CEPE. Así, los niveles de los CELA corresponden a los cursos de español, cuyos contenidos, a su vez, están homologados con los del MCER.

Una de las características de los CELA es, precisamente, que evalúan la lengua por niveles: inicial, intermedio y superior, satisfaciendo así, a diferencia del EPLE y del $\mathrm{CIE}$, Ias necesidades de los alumnos.

Otra característica que marca la diferencia entre los distintos exámenes es el ámbito que cubren. Tanto el EPLE como el CIE están enfocados hacia el ámbito académico; es decir, quienes solicitan el EPLE son en su mayoría estudiantes extranjeros que desean ingresar a una licenciatura o posgrado de la UNAM y para ello es requisito indispensable demostrar el dominio del español en un grado suficientemente al to como para poder seguir estudios universitarios. LOS CELA, en cambio, fueron diseñados para cubrir principal mente los ámbitos personal, público y profesional, de los interesados, esto significa que 
Beatriz Granda, Lineamientos generales para la elaboración de exámenes CELA. Nivel superior.

Campos y Matínez, Lineamientos generales para la elaboración de exámenes CELA. Nivel intermedio.

los candidatos no necesitan el examen para ingresar a una carrera o un posgrado universitario, sino que son personas que requieren probar su dominio del español para desenvolverse en su ambiente laboral o social.

A continuación se presentan al gunas de las características específicas de cada uno de los niveles del CELA.

El CELA I nicial evalúa el conocimiento que posee el estudiante de la lengua hasta el nivel B1 (Nivel Umbral). La obtención del documento avala un nivel de competencia comunicativa suficiente para "interactuar social mente en situaciones relacionadas con la vida cotidiana y para comunicar de forma básica, experiencias personales, planes, opiniones, deseos y necesidades". ${ }^{3}$

El CELA Intermedio evalúa el nivel B2 del MCER (nivel avanzado). Con este examen se avala la capacidad para desenvolverse adecuadamente en situaci ones que van más allá de la supervivencia básica. El candidato que logra el mayor puntaje:

[...] lee adaptando estilo y vel ocidad; posee amplio vocabulario e interpreta aspectos pragmáticos de la lengua; escribe textos de forma clara y detall lada sobre temas variados de interés social; argumenta su punto de vista; emplea vocabulario con ingenio y riqueza en cartas, informes, narraciones, críticas; sigue las ideas principales de un debate; comprende la mayor parte de programas de televisión, se expresa eficazmente con espontaneidad, narra, argumenta, expresa queja y participa activamente en conversaciones y debates. ${ }^{4}$

\section{EL CELA SUPERI OR (VERSIÓN 2)}

Este examen evalúa los niveles C1 y C2 del MCER. Lo que acredita el nivel superior es la capacidad, por parte del candidato, de llevar a cabo interacciones de todo tipo, incluso delicadas y complejas; de comprender textosorales y escritos de diferentes tipos, registros, géneros y variantes del español; seguir sin dificultad programas de radio o de tel evisión, diálogos de películas o de obras de teatro; entender textos que incorporan informaciones principales y secundarias y percibir las relaciones entre ambas, 
así como la estructura gl obal del texto, incluso, cuando no aparece explícitamente señalada; interpretar la mayor parte de las expresiones coloquiales, significado de refranes y los giros idiomáticos habituales entre los hablantes nati vos; util izar todo tipo de nexos retóricos y marcadores discursivos para organizar su discurso oral y escrito.

Al igual que el CELA nivel inicial eintermedio, el superior (versión 2) está dirigido a un público menos especializado y más general; es decir, todos aquellos aspirantes que no están vinculados a los estudios, como pueden ser los diplomáticos de diferentes países que tienen que interactuar con hablantes de español y personal que labora en embajadas; así como prestadores de servicios que tienen que desenvolverse en español, mujeres y hombres que por razones diversas tienen que vivir en países de habla hispana y que requieren o desean obtener un documento oficial que respal de su conocimiento de la lengua, ya sea que ésta haya sido aprendida de manera escolarizada o en forma práctica.

Para este público, heterogéneo en esencia, la propuesta del CELA Superior (versión 2) es que los sustentantes sean capaces de comunicarse en español de manera efectiva y apropiada en un nivel avanzado.

Los fundamentos teóricos que se tomaron en cuenta para el diseño de este examen son el modelo de competencia comunicativa de Backman (1990) ${ }^{5}$ y un modelo de examen de certificación propuesto por Anzal dúa, ${ }^{6}$ pero con al gunas modificaciones. ${ }^{7}$

Si bien, en el CELA Superior (versión 2) se evalúan las cuatro destrezas que tradicionalmente se han venido manejando en la enseñanza de lenguas, más la competencia lingüística, sin duda son la expresión oral y escrita las que más peso tienen en la ponderación total del examen, pues consideramos que es en las habilidades de producción donde se refleja de mejor manera el nivel de los sustentantes.

Una característica de este examen que lo diferencia de I os demás del sistema, es el hecho de probar las habilidades de manera integrada; esto es, a partir de la comprensión auditiva y de lectura, los candidatos escriben y hablan sobre temas relacionados.
LyleF. Bachean, Fundamental Considerations in a Language Testing.

6 Josué Andaldúa, Diseño de un modelo de evaluación para tres niveles de certificación del español como lenguaje extranjero.

7 Campos et.al., Lineamientos generales para la elaboración de examenes CELA. Nivel superior. Anexo 1. 
La crítica recurrente hacia la evaluación de las habilidades de producción hace hincapié en el grado de subjetividad por parte del evaluador -que necesariamente se presenta-y la dificultad para calificarlas. En los CELA, conscientes de esto, se ha puesto especial empeño en el diseño de las tareas de producción, así como en las escalas para cal ificarlas, pues consideramos que contar con tareas lo suficientemente delineadas para orientar la producción (oral y escrita) de los candidatos hasta al canzar los niveles $\mathrm{C} 1$ y C2 y tener pautas claras y precisas para calificarlas, reducirán al máximo la subjetividad del evaluador.

Por todo lo anterior, podemos afirmar que los CELA son los exámenes idóneos para quienes (como los estudiantes del CEPE), se encuentran a medio camino en su proceso de aprendizaje o adquisición de la lengua, y aun así, podrán obtener un documento oficial que avale sus conocimientos.

Hasta aquí, hemos intentado mostrar un panorama muy general sobre la certificación, se describió cada uno delos instrumentos que conforman el sistema de certificación del CEPE y se mencionaron las características del CELA Superior (versión 2), ya que es este examen el que completa el proyecto CELA.

BiBLIOGRAFía

ALDERSON, Charles] ., et. al., Exámenes de idiomas. Elaboración y evaluación. Vers. esp. de Neus Figueras. Madrid, Cambridge University Press, 1998.

ANZALDÚA, J osué, Diseño de un modelo de evaluación para tresniveles de certificación del español comolengua extranjera. México, 2001, Tesis, México. Universidad Pedagógica Nacional.

BACHMAN, LyleF., Fundamental Considerations in Language Testing. Oxford University Press, 1990.

CAMPOS y MARTínEZ, Lineamientos generales para la elaboración de exámenes CELA. Nivel intermedio, 2006. (En prensa) 
CAMPOS, et. al., Lineamientos generales para la elaboración de exámenes CELA. Nivel superior. (En prensa) GRANDA, Beatriz, Lineamientos Generales para la elaboración de exámenes CELA. Nivel superior. 2007. (En prensa)

J URADO, Martha, Desarrollo de un modelo de examen para un nuevo sistema de certificación internacional denominado Certificado Internacional del Español. México, CEPE-UNAM, 2006.

Marco Común Europeo de Referencia para las Lenguas: aprendizaje, enseñanza, evaluación [en línea]. < http:/ / cvc.cervantes.es/ obref/ marco/ presentacion.htm> . [Consulta: 30 de marzo, 2007.] PARRONDO, Rodríguez, J osé Ramón, Sistema Internacional de Certificación del Español. Documento de trabajo para el IV Congreso Internacional de la Lengua Española, 2006. 
